Journal of Applied Pharmaceutical Science Vol. 6 (12), pp. 136-143, December, 2016

Available online at http://www.japsonline.com

DOI: $10.7324 /$ JAPS.2016.601219

ISSN 2231-3354 (cc)) BY-NC-SA

\title{
Simple Spectrophotometric and Conductometric Methods for Determination of Gemifloxacin in Pure, Pharmaceutical Dosage Form and Human Urine
}

\author{
Dalia Zidan ${ }^{1 *}$, Omnia A. Ismaiel ${ }^{2}$, Wafaa S. Hassan ${ }^{2}$, Abdalla Shalaby ${ }^{2}$ \\ ${ }^{1}$ Aga Health Insurance Hospital, Dakahlia. \\ ${ }^{2}$ Department of Analytical Chemistry, Faculty of Pharmacy, Zagazig University, Zagazig 44519, Egypt.
}

\begin{tabular}{l} 
ARTICLE INFO \\
\hline Article history: \\
Received on: $17 / 09 / 2015$ \\
Revised on: 09/01/2016 \\
Accepted on: 03/03/2016 \\
Available online: 28/12/2016 \\
\hline Key words: \\
Gemifloxacin, \\
Phosphomolybdic Acid, \\
Pharmaceutical Preparations, \\
Human Urine, \\
Spectrophotometry, \\
Conductometry, IR \\
spectroscopy.
\end{tabular}

\begin{abstract}
Two Simple, accurate, precise, and rapid spectrophotometric and conductometric methods were developed for the estimation ofgemifloxacin (GEM) in pharmaceutical dosage forms and biological human urine. Method A: A spectrophotometric method is based on the oxidation reaction between phosphomolybdic acid (PMA) and GEM to form molybdenum blue $\left(\mathrm{Mo}^{+5}\right)$. Beer's law was obeyed in the concentration range of $(5-27 \mu \mathrm{g} / \mathrm{ml})$. The correlation coefficient $(r 2)$ for the studied drug was found to be 0.9999 . The molar absorptivity $(\varepsilon)$, Sandell's sensitivity, limit of detection (LOD), and limit of quantitation (LOQ)were also calculated. Method B: A conductometric method is based on formation of an ion associate with PMA. It involves direct titration with PMA in the range of 1-20 mg. The precipitate obtained by ion pairing GEM with PMA has been spectroscopically characterized using IR spectroscopy. The method was successively applied to pharmaceutical formulations containing GEM. The results obtained were favorably compared with those obtained using the reported method.
\end{abstract}

\section{INTRODUCTION}

Gemifloxacin is chemically designated as (R,S)-7[(4Z)-3-(aminomethyl)-4-(methoxyimino)-1 -pyrrolidinyl]-1cyclopropyl-6-fluoro-1,4-dihydro-4-oxo-1,8 -naphthyridine-3carboxylic acid (schem 1a) (Martindale and Sweetman, 1999), has antibacterial activity against bothgram-positive bacteria and gram-negative bacteria and used for thetreatment of respiratory tract infections (Martindale and Sweetman, 1999; Lopez et al., 2001). Mechanism of antibacterial action of gemifloxacin depends on blocking of bacterial DNA replication through binding itself to DNA gyrase enzyme, allowing the untwisting required to replicate one DNA double helix into two.

\footnotetext{
* Corresponding Author

Email: daliazidan29 @ yahoo.com
}

The drug has 100 times higher affinity for bacterial DNA gyrase than for mammalian. It also causes inhibition of the enzymes topoisomerase II (DNA gyrase) and topoisomerase IV, which are required for bacterial DNA replication, transcription, repair, and recombination (Blondeau, 2004). Various methods have been reported for the determination of GEM. Those methods are the various spectrophotometric techniques (Hassan et al., 2014; Gouda et al., 2014), high performance liquid chromatography (Gumustas and Ozkan, 2012; Nageswara Rao et al., 2012; Kaiser et al., 2011; Sultana et al., 2011; Al-Hadiya et al., 2010), capillary electrophoresis (Elbashir et al., 2008), microchip electrophoresis (Cho et al., 2004), chemiluminescence (Zhao et al., 2013), LCmass spectrometry (Roy et al., 2010; Robledo and Smyth, 2008; Doyle et al., 2000), and potentiometry (Al-Mohaimeed et al., 2012). These methods were related to some major drawbacks such as having inadequate sensitivity, being time-consuming, tedious and sophisticated sample preparation. 
The majority of the reported methods are HPLC methods which require complex and expensive equipment, intensive sample preparation, and also require personal skills in chromatographic techniques.

Also, Due to weak UV absorbance of quinolone antibiotics, it is difficult to develop a simple method for analysis of the drugs in pharmaceutical applications and biological fluids using conventional UVdetection, so there is a need for simple spectrophotometric and conductometric method for the analysis of the cited drug in pharmaceutical formulations. In this study we develop simple, sensitive and accurate spectrophotometric and conductometric methods. The application of PMA to the spectrophotometric and conductometric determination of gemifloxacinin its pure, pharmaceutical preparation and to the human urine after extraction using acidified methylene chloride has also been used successfully. Additionally, structural elucidation of GEM-PMA ion associate was performed using IR spectroscopy.

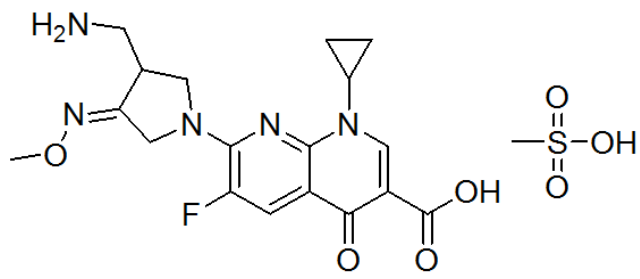

Scheme1 $1_{a}$. Chemical structure of gemifloxacin.

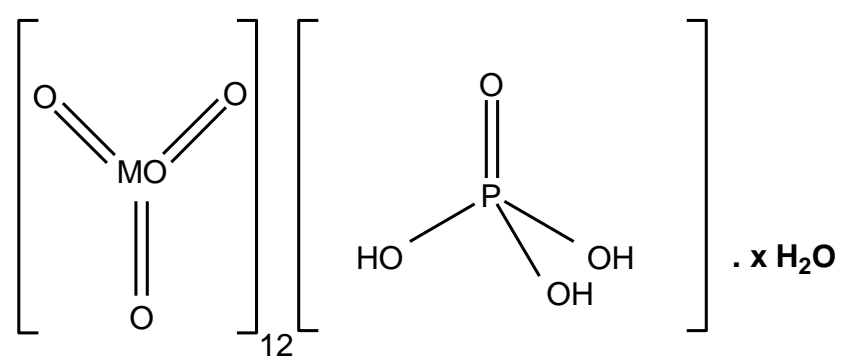

Scheme1 $1_{b}$. Chemical structure of phosphomolybdic acid

\section{EXPERIMENTAL}

\section{Instruments}

- Spectrophotometric measurements were done using a Shimadzu UV-Visible 1601 PC Spectrophotometer (Kyoto, Japan $\mathrm{P} / \mathrm{N}$ 206-67001) equipped with $10 \mathrm{~mm}$ matched quartz cell.

-Conductometer model 470 portable conductivity/ JENWAY meter, 25 DEG.C-F10 dip-type cell was used with acellconstant, Kcell, of 1.10.

-IR measurements were recorded as $\mathrm{KBr}$ disks using Mattson 1000 spectrophotometer.

\section{Reagents and Materials}

All chemicals and materials were of analytical grade, and double distilled water was used throughout the work.

- Gemifloxacin mesylate (claimed purity, >98\%) were purchased from Sigma-Aldrich (St. Louis, MO, USA).
- Factive $^{\circledR}$ tablet equivalent to $320 \mathrm{mg}$ gemifloxacin were obtained from local pharmacy.

- Phosphomolybdic acid obtained from (Aldrich, Germany) $1 \% \mathrm{w} / \mathrm{v}$ and $5^{*} 10^{-3} \mathrm{M}$ were prepared in double distilled water for method (A) and (B), respectively.

- Hydrochloric acid, ethanol, methanol and acetone purchased from (El- Nasr Pharmaceutical Chemicals Company (ADWIC), Cairo, Egypt).

- Blank human urine was collected from healthy volunteers stored at $-20^{\circ} \mathrm{C}$.

\section{Preparation of Standard Solutions}

Standard solution of Gemifloxacin for method A and method B was prepared fresh, as required, by dissolving the appropriate amount of GEM in doubled distilled water to provide $1 \mathrm{mg} / \mathrm{ml}$. The standard solutions must be stored under lightprotected conditions at about $4{ }^{\circ} \mathrm{C}$.

\section{Recommended Procedures and Calibration Curves Method A: Spectrophotometric assay procedure for pure drug}

Into a series of $10 \mathrm{ml}$ volumetric flasks, aliquots of drug solutions equivalent to $5-27 \mu \mathrm{g} / \mathrm{mL}$ for GEM were transferred. To each flask $2 \mathrm{~mL}$ of $0.1 \mathrm{~N} \mathrm{Hcl}$ and $0.2 \mathrm{~mL}$ of $1.0 \%$ of PMA were added. These solutions were mixed by shaking and placed for 45 min in a boiling water-bath. After completion of the heat treatment, the solution was cooled immediately to room temperature using a cold water-bath. The resulting blue solution was diluted to the mark with ethanol. The absorbance of the blue solution was measured at maximum absorbance $794 \mathrm{~nm}$ against a reagent blank that had been treated similarly.

\section{Method B: Conductometric Measurements}

Aliquots of the standard drug solution containing 1-20 $\mathrm{mg}$ of GMF were transferred to a $50 \mathrm{ml}$ titration cell and the volume was made to the mark with water. The conductivity cell was immersed in titration cell and the solution was titrated with 5 $\mathrm{x} 10^{-3} \mathrm{M}$ of the PMA. The conductance was determined after stirring for 2 minutes subsequent each addition of the reagent. A conductivity (corrected for dilution) versus volume for the added titrant was constructed and the end point was determined. Corrected for dilution effect was calculated according to the following equation, (assuming that conductivity is a linear function of dilution):

Corrected conductivity $=$ the observed electrolytic conductivity ((initial volume + volume of the reagent added)/ (initial volume)).

The nominal content of MVH was calculated using the following equation:

Amount of the drug $=(\mathrm{V} \times \mathrm{MWT} \times \mathrm{M}) / \mathrm{N}$ Where

$\mathrm{V}=$ volume $(\mathrm{mL})$ of the titrant consumed in the titration, MWT $=$ relative molecular mass of the analyte, $\mathrm{M}=$ molarity of the titrant, and $\mathrm{N}=$ number of moles of the titrant consumed per one mole of the analyte. A graph of corrected conductivity versus the volume of added titrant was constructed and end point was determined (Fig 7). 


\section{Preparation of ion-associates for IR method}

The ion associate was prepared by mixing solutions containing 0.01 M of PMA, and the requisite amount of GEM. The precipitate obtained was filtered, washed with water, and then dried at room temperature. The precipitate was subjected to IR spectroscopy.

\section{Assay procedure for tablets}

Twenty tablets were weighed and finely powdered. A quantity of the powder contain $100 \mathrm{mg}$ of the active ingredient was weighted accurately then transferred into a $100 \mathrm{~mL}$ conical flask and dissolved with $30 \mathrm{ml}$ of double distilled water. After shaking for $15 \mathrm{~min}$, the contents were filtered into a100 $\mathrm{ml}$ volumetric flask. The conical flask was washed with little amount of distilled water. The washing was passed into the same volumetric flask. The volume was completed to the mark with double distilled water. The nominal content of the active component in tablets was determined either from the previously plotted calibration graphs or using the corresponding regression equations.

\section{Procedure for spiked urine}

Different quantities of gemifloxacin $(1 \mathrm{mg} / \mathrm{ml})$ were transferred to $10 \mathrm{ml}$ volumetric flasks and the volume was adjusted to the mark with urine. $1 \mathrm{ml}$ from each flask was taken and $2 \mathrm{ml} 1$ $\mathrm{N} \mathrm{Hcl}$ and $4 \mathrm{ml}$ methylene chloride were added. Shake well and centrifugation was done for $5 \mathrm{~min}$ at $3500 \mathrm{rpm}$. Evaporate the methylene chloride extract under a stream of nitrogen till dryness. Dissolve in $1 \mathrm{ml}$ water and proceed as described under spectrophotometric assay for pure drug.

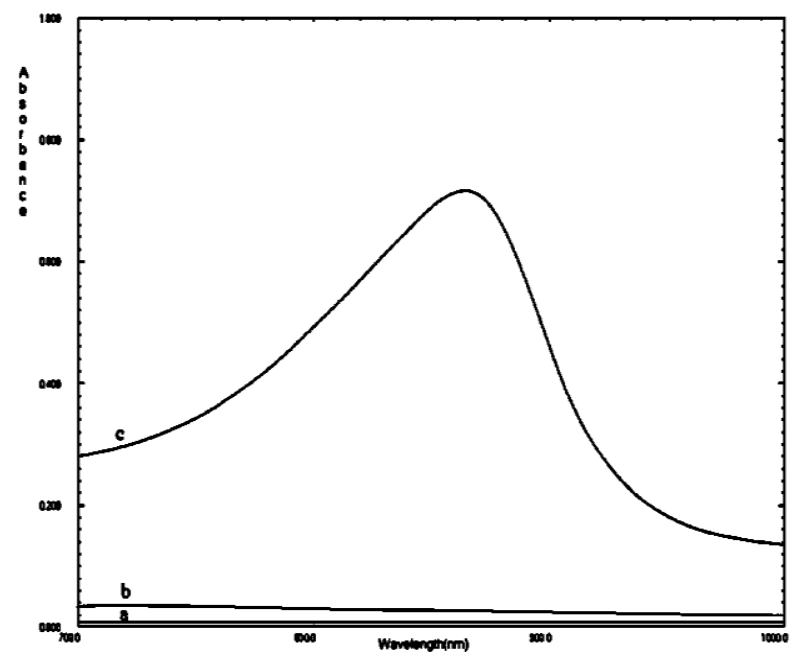

Fig. 1: Absorption spectra for (a) gemifloxacin solution $22 \mu \mathrm{g} / \mathrm{ml}$, (b) blank (c) Absorption spectrum of the reaction product from the reaction of $22 \mu \mathrm{g} / \mathrm{ml}$ gemifloxacin with phosphomolybdic acid.

\section{RESULTS AND DISCUSSION}

\section{Optimization of Variables}

For method A; the electronic spectrum of the reaction of GEM and PMA is shown in fig (1). The reaction gave a maximum absorption peak at $794 \mathrm{~nm}$. Investigations were carried out to establish the most favorable conditions for maximum colour development for spectrophotometric method (method A) while for conductometric method (method B) using PMA as an ion pairing reagent for GEM. The optimum conditions for performing the titration in a quantitative manner more elucidated as described below.

\section{Conditions for method A \\ Effect of acid type}

In a trial to determine the most suitable acid used with phosphomolybdic acid, the effect of acetic, hydrocholoric and sulfuric acid was examined. It was found that hydrochloric gave maximum and reproducible colour intensity (fig 2).

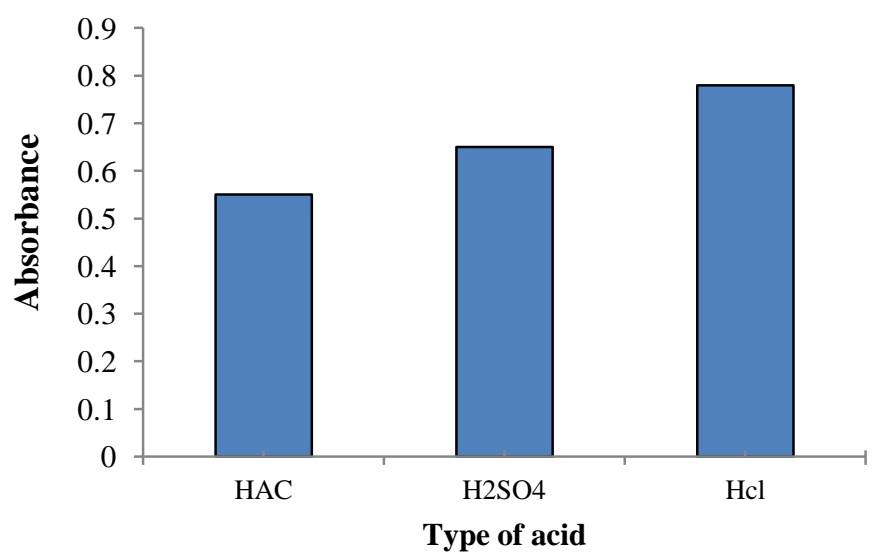

Fig. 2: Effect of acid type.

\section{Volume of acid effect}

After trying on several volumes $0.5,1,1.5,2,2.5 \mathrm{ml}$ of hydrochloric acid for GEM to elucidate the optimum volume for quantitative estimation of the studied drug, it was found that optimum volume is $2 \mathrm{~mL}$ for both drugs (fig 3 ).

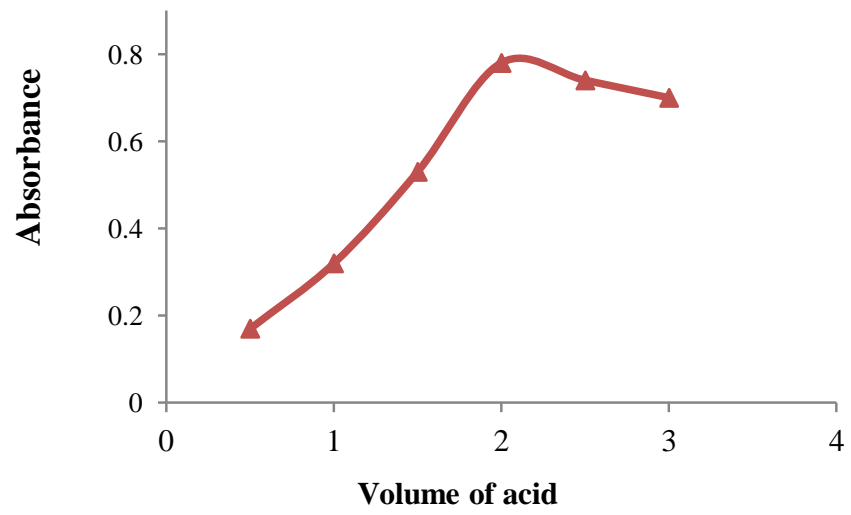

Fig. 3: Volume of $\mathrm{HCl}$ acid.

\section{Volume of reagent effect}

The volume of reagent that gave reproducible colour intensity and highest constant absorption was found to be $0.2 \mathrm{~mL}$ for GEM (fig 4). 


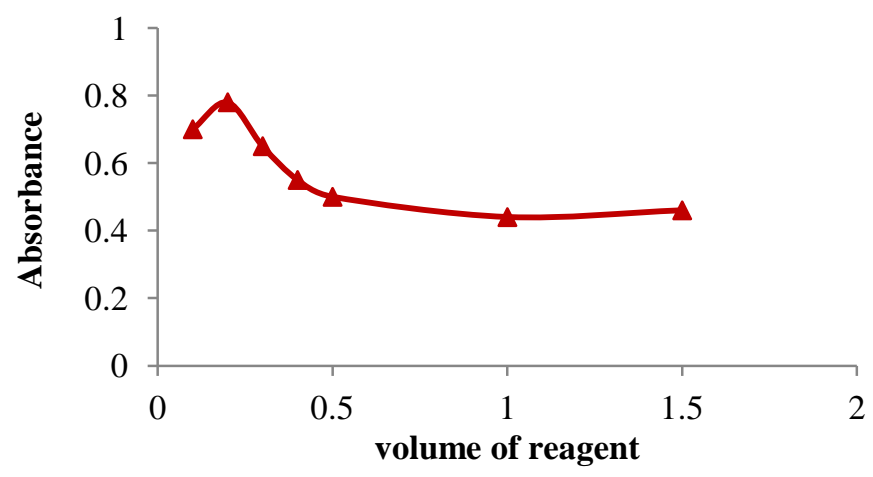

Fig. 4: Volume of reagent.

\section{Heating time effect}

It was found that heating in boiling water bath for 40 min. give maximum colour intensity (fig 5).

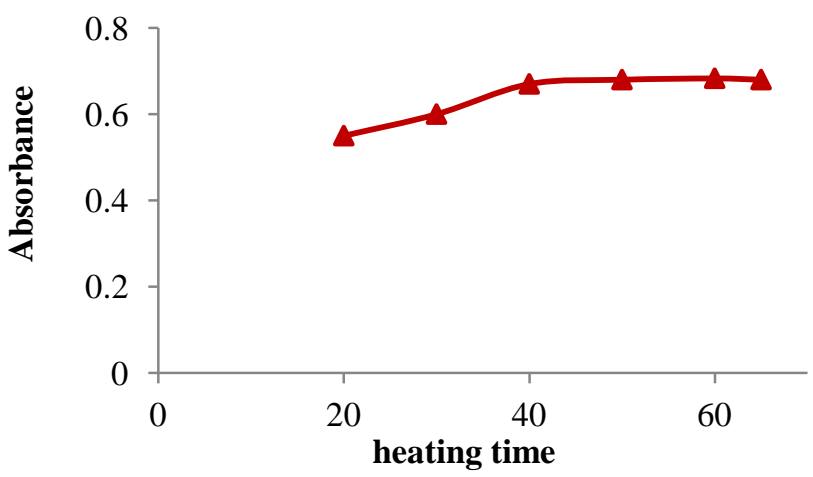

Fig. 5: Heating time.

\section{Effect of Sequence of addition}

From the trials on the sequence of addition, it was found that order of addition had no effect on the reaction of both drugs.

\section{Colour stability} hour (fig 6).

The colour intensity was found to be stable for about one

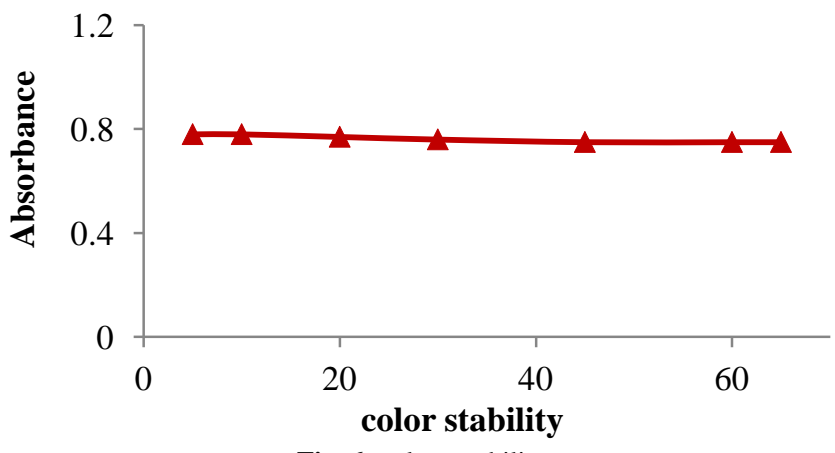

Fig. 6: colour stability.

Determination of Stoichiometric Balance Using Molar Ratio Method (Yoe and Jones, 1944)

The stoichiometric reaction between the cited drug and PMA was studied by molar ratio method using an equimolar $\left(5 \times 10^{-3} \mathrm{M}\right)$ solution of the cited drug and PMA of the same molarities. The obtained results showed that the composition of the complexe was 1:1.

GEM.CH3SO3-H+ + H3(PMA) $\rightarrow\{[$ GEM $][H 2(\mathrm{PMA})]\}(\mathrm{S})+\mathrm{H}+$.

\section{Conditions for method B}

Investigations were carried out to estimate the most suitable conditions for the complex formed from the cited drugs with PMA to obtain the sharp endpoint. The optimum conditions for performing the titration in a quantitative manner were described later.

\section{Reaction medium}

Reaction medium titrations in different media were attempted to obtain the best results. Preliminary experiments were in:

1) Aqueous drug solution prepared by dissolving $100 \mathrm{mg}$ drug in $100 \mathrm{ml}$ water with aqueous reagent solution.

2) Ethanol drug solution with ethanol reagent solution,

3) Drug solution with reagent solution, both in ethanolwater $(50 \%, \mathrm{v} / \mathrm{v})$ mixture,

4) Methanol drug solution with methanol reagent solution,

5) Drug solution with reagent solution, both in methanolwater mixture $(50 \% \mathrm{v} / \mathrm{v})$,

6) Drug solution with reagent solution, both in acetonewater $(50 \% \mathrm{v} / \mathrm{v})$ mixture.

From the previous Preliminary experiments, it was found that there is no effect of the pervious experiment except for acetone in shifting end point.

\section{Reagent Concentration}

Different concentrations of PMA solution were tried ranging from $5 \times 10^{-4}$ to $5 \times 10^{-3}$ molar solutions. The optimum concentration of the reagent was found to be $5 \times 10^{-3} \mathrm{M}$ in titration of the studied drug in order to achieve a constant and highly stable conductance readingin 2 min of mixing. Concentrations less than these Limits led to unstable readings, and more time was needed to achieve constant values of conductance.

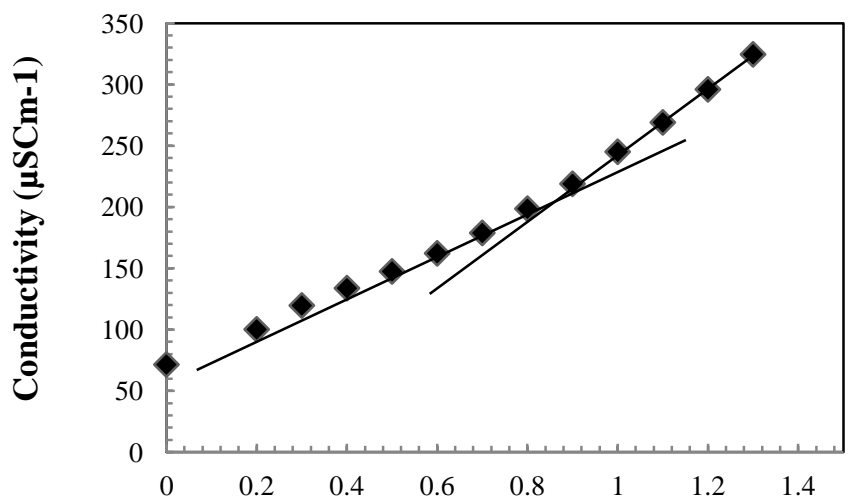

Volume of phosphomolybdic acid(ml) (mL)

Fig. 7: Conductometric titration curve of $2 \mathrm{mg}$ gemifloxacin versus $5 \times 10^{-3} \mathrm{M}$ phosphomolybdic acid. 
Titration curve in (Fig.7) showed two straight lines intersected at the end point; the first line ascending, and the second has conductance values that would slightly increase after the equivalence point. This increase may be due to the formation of ion associate. After the end-point, the titration curves showed slightly increase in the value of conductance, despite the excess of the reagent. This may be due to further ionic condensation, leading to species of lower mobility. A curve break is noted at drugreagent molar ratio 1:1. This molar ratio also ascertained through spectrophotometric determination (method A). The results from the conductometic titrations are summarized in Table 6 . The data show that accurate results were obtained with good recoveries and low standard deviation values. The optimum concentration range for determination of the cited drug was in the range of $1-20 \mathrm{mg}$. At such ranges, sharp inflection (Fig.7) and stable conductance reading were obtained.

\section{Method Validation}

\section{For method A}

Linearity

Under the optimum conditions described, standard calibration curves for gemifloxacin with acidified phosphomolybdic acid was constructed by plotting the values of the absorbance versus the final concentrations of the drug $(\mu \mathrm{g} \mathrm{mL}$ 1). Beer'slaw was obtained in the concentration range of the final dilution of the cited drug in Table 1. Beer's law was constructed over the concentration ranges of $5-27 \mu \mathrm{g} / \mathrm{mL}$ for GEM Table 2. The linear regression equation for the cited drug was listed in Table 1.The correlation coefficient was 0.9999 for GEM indicating good linearity over the working concentration range.

Table 1: Quantitative parameters for the spectrophotometric determination of gemifloxacin.

\begin{tabular}{|c|c|}
\hline Parameter & GEM \\
\hline Kmax(nm) & 794 \\
\hline Beer's law ranges $(\mu \mathrm{g} / \mathrm{ml})$ & $5-27$ \\
\hline \multicolumn{2}{|l|}{ Regression equation $* *$} \\
\hline Slope (a) & 0.0365 \\
\hline Intercept (b) & -0.0371 \\
\hline Correlation coefficient $\left(\mathrm{r}^{2}\right)$ & 0.9999 \\
\hline $\operatorname{LOD}(\mu \mathrm{g} / \mathrm{ml})$ & 4.49 \\
\hline $\mathrm{LOQ}(\mu \mathrm{g} / \mathrm{ml})$ & 13.47 \\
\hline Ringbom optimum concentration range $(\mu \mathrm{g} / \mathrm{ml})$ & $5-22$ \\
\hline Sandell's sensitivity $\left(\mu \mathrm{g} \cdot \mathrm{cm}^{-2}\right)$ & 0.03 \\
\hline$\varepsilon\left(x 10^{4}\right) \mathrm{L} \cdot \mathrm{mol}^{-1} \cdot \mathrm{cm}^{-1}$ & 1.8 \\
\hline Molar ratio & $1: 1$ \\
\hline
\end{tabular}

\section{Sensitivity}

The limit of detection (LOD) of the method was calculated according to the ICH and FDA guidelines (Guideline, 2005; Food and Administration, 2001) using the following equation:

$$
\mathrm{LOD}=3.3 \sigma / \mathrm{S}
$$

Where $\sigma=$ the standard deviation of replicate blank responses (under the same conditions as for sample analysis), andS =the slope of the calibration curve.
While the limit of quantitation calculated from the following equation:

$$
\mathrm{LOQ}=10 \sigma / \mathrm{S}
$$

The calculated values of LOD and LOQ were calculated as in Table 1 confirmed the sensitivity of the proposed method.

Table 2: Spectrophotometric Determination of Gemifloxacin In Bulk Powder.

\begin{tabular}{ccc}
\hline Taken $(\boldsymbol{\mu g} / \mathbf{m l})$ & Found $(\boldsymbol{\mu g} / \mathbf{m l})$ & \%Recovery \\
\hline 5 & 5.1 & 102.05 \\
7 & 6.86 & 97.94 \\
10 & 10.06 & 100.63 \\
15 & 15 & 100 \\
17 & 16.93 & 99.62 \\
22 & 22.07 & 100.31 \\
23 & 22.94 & 99.72 \\
25 & 24.94 & 99.78 \\
27 & 27.06 & 100.24 \\
\hline Mean 100.03 & & \\
ISD1.08 & & \\
\%RSD1.08 & & \\
\%Er0.03 & &
\end{tabular}

\section{Accuracy and Precision}

The inter and intraday accuracy and precision were determined by preparing three different concentration of each drug and each concentration is analysed in 11 replicates. The relative standard deviation as a precision (RSD \%) and percentage relative error (Er\%) as accuracy of the suggested method were calculated. The RSD \% and Er\% can be calculated according the following equations:

$\mathrm{RSD} \%=(\mathrm{SD} / \mathrm{mean}) * 100$ And

Er\% $=[($ found-added $) /$ added $] * 100$

Where $\mathrm{SD}=$ the standard deviation of replicate responses of one concentration.

The analytical results for accuracy and precision (Table 3) showed that the proposed method has good repeatability and reproducibility.

Table 3: Intra- and inter-day precision and accuracy of GEMusing the

\begin{tabular}{|c|c|c|c|c|c|c|c|c|}
\hline \multirow{2}{*}{ 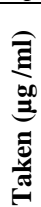 } & \multicolumn{4}{|c|}{ Inter-day(n=11) } & \multicolumn{4}{|c|}{ Intra-day $(n=5)$} \\
\hline & 䦠 & 离 & 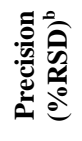 & 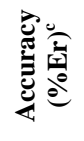 & 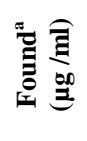 & o & 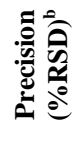 & 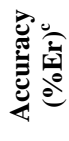 \\
\hline 7 & 7.01 & 100.19 & 1.26 & 0.19 & 7.04 & 100.50 & 0.012 & 0.503 \\
\hline 17 & 17.044 & 100.26 & 1.02 & 0.26 & 17.11 & 100.62 & 0.004 & 0.621 \\
\hline 25 & 25.004 & 100.02 & 0.79 & 0.02 & 25.01 & 100.05 & 0.434 & 0.047 \\
\hline
\end{tabular}
proposed method A.

\section{For method B}

The validity of the proposed method can be estimated using statistical analysis of the data obtained from its application on the cited drug in the pure form and in the formulation was performed. The results revealed in Table 4 showed that the proposed method is 


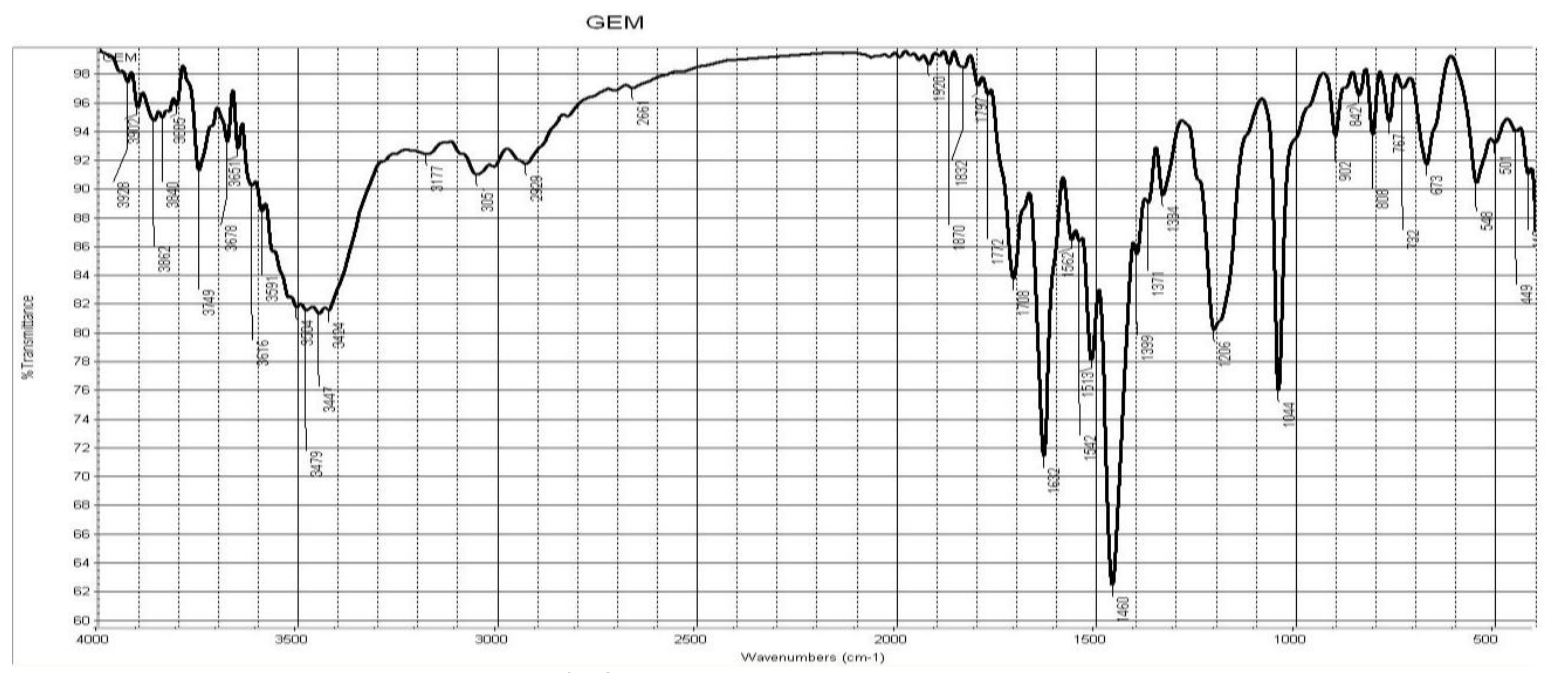

Fig. 8: FT-IR spectrum of gemifloxacin.

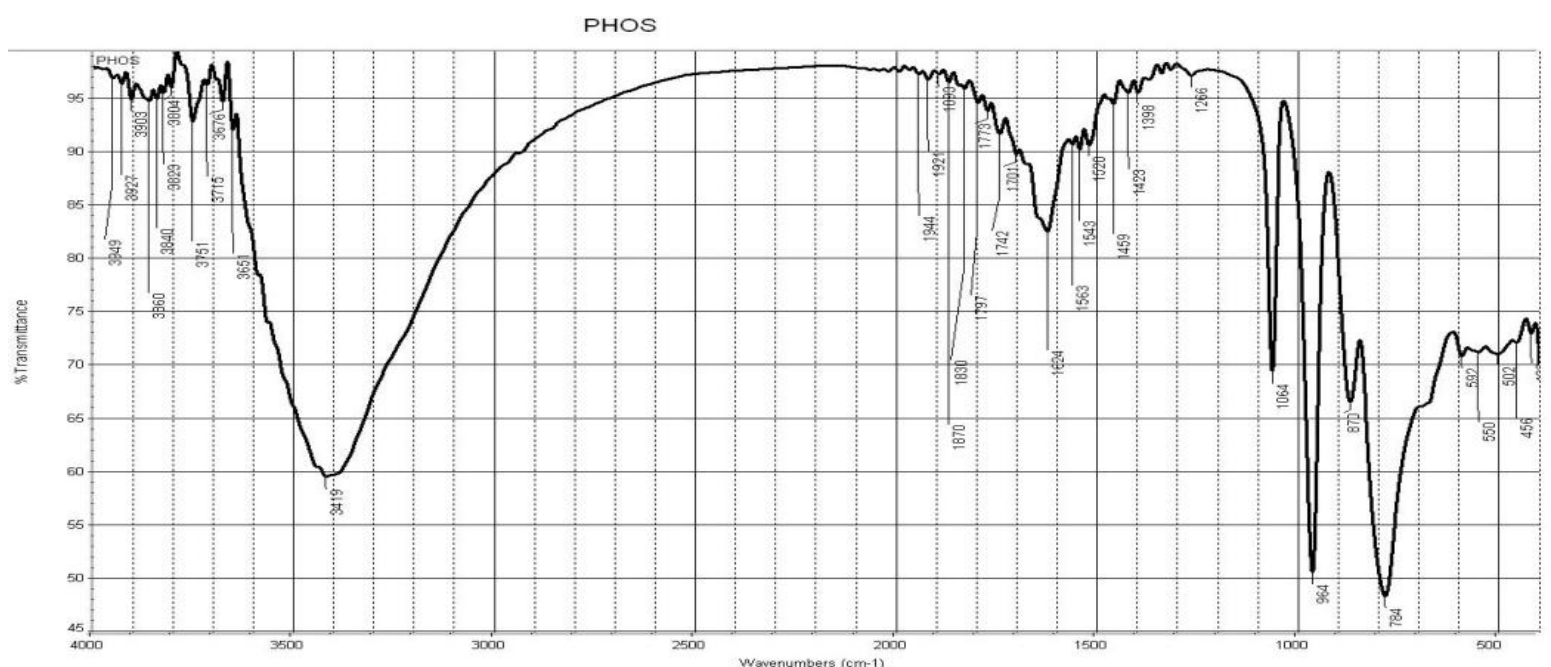

Fig. 9: FT-IR spectrum of PMA.

Gem-Phosph

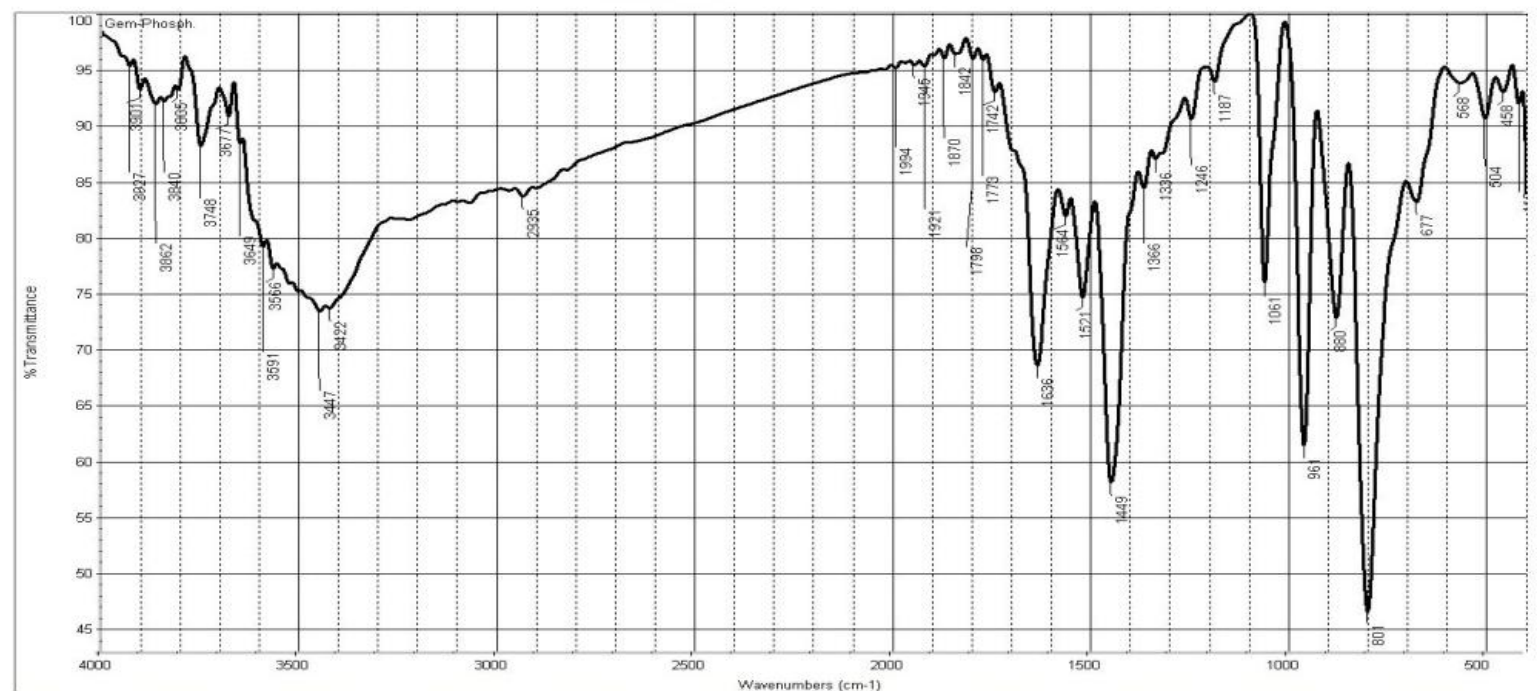

Fig. 10: FT-IR spectrum of gemifloxacin and PMA. 
satisfactorily accurate, precise, and reproducible over a concentration range of $1-20 \mathrm{mg}$.

Table 4: Conductometric Determination of Gemifloxacin using phosphomolybdic Acid.

\begin{tabular}{ccc}
\hline Taken $(\mathbf{m g})$ & Found $(\mathbf{m g})$ & \% recovery \\
\hline 1 & 1 & 100.00 \\
2 & 2 & 100.00 \\
5 & 5.08 & 101.60 \\
7 & 7.11 & 101.57 \\
9 & 9.09 & 101.00 \\
15 & 15.1 & 100.67 \\
20 & 20.15 & 100.75 \\
Mean & & 100.79 \\
\pm SD & & 0.66 \\
\%SD & & 0.65 \\
$\%$ Er & & 0.80 \\
\hline
\end{tabular}

\section{Analytical Applications.}

\section{For method A.}

The analytical application of the proposed method to the studied drug in its pharmaceutical dosage form and in biological human urine was determined. Satisfactory results were obtained. The recovery of the cited drug was calculated by comparing the concentration obtained from the spiked mixtures with those of the drug. The results of analysis of the commercial dosage form and the recovery study are shown in Tables 5, 6 .

Table 5: Application of the proposed spectrophotometric method to the determination of gemifloxacin in its pharmaceutical dosage form

\begin{tabular}{ccc}
\hline & Factive $^{\circledR}$ tablet \\
\hline Taken $(\mu \mathrm{g} / \mathrm{ml})$ & Found $(\mu \mathrm{g} / \mathrm{ml})$ & \% recovery $^{*}$ \\
\hline 7 & 7.09 & 101.28 \\
10 & 10 & 100.00 \\
15 & 15.21 & 101.39 \\
17 & 16.92 & 99.510 \\
22 & 22.06 & 100.26 \\
25 & 24.80 & 99.190 \\
Mean & & 100.28 \\
\pm SD & & 0.9 \\
\% & & 0.901 \\
\hline Er & & 0.28 \\
\hline
\end{tabular}

*average of three determination

Table 6: Application of the proposed spectrophotometric method to the determination of gemifloxacin in spiked human urine.

\begin{tabular}{ccc}
\hline Taken $(\mu \mathrm{g} / \mathrm{ml})$ & Found $(\mu \mathrm{g} / \mathrm{ml})$ & \%Recovery \\
\hline 10 & 10.11 & 101.11 \\
15 & 15.15 & 101.03 \\
17 & 17.17 & 101.01 \\
22 & 22.08 & 100.35 \\
25 & 25.02 & 100.07 \\
27 & 27.07 & 100.25 \\
\hline Mean \pm SD & & $100.64 \pm 0.461$ \\
\%RD & & 0.358 \\
\%Er & & 0.636 \\
\hline
\end{tabular}

\section{For method B.}

Satisfactory results were obtained from the application of the proposed method in its pharmaceutical dosage form as shown in table 7. The results that obtained were compared with the reported method (Ebraheem et al., 2011). There is no significant differences were found between the proposed methods and reported method. Statistical comparison of the results was performed using Student's t test and variance ratio F-test at 95\% confidence level (Table 8).

Table 7: Conductometric determination of gemifloxacin using phosphomolybdic acid in the IR dosage forms.

\begin{tabular}{ccc}
\hline & Factive $^{\circledR}$ tablet & \\
\hline Taken $(\mathrm{mg})$ & Found $^{\mathrm{a}}(\mathrm{mg})$ & \%recovery \\
\hline 2 & 2 & 100 \\
4 & 4.05 & 101 \\
6 & 6.03 & 100.5 \\
8 & 8 & 100 \\
10 & 10.01 & 100. \\
12 & 12.04 & 100.3 \\
14 & 14.01 & 100.3 \\
Mean \pm SD & & $100.79 \pm 0.66$ \\
\% RSD & & 0.65 \\
\%Er & & 0.8 \\
\hline
\end{tabular}

Table 8: Statistical data for determination of GEM in its dosage form using spectrophotometric method with PMA

\begin{tabular}{cccc}
\hline \multirow{2}{*}{ Items } & \multicolumn{3}{c}{ Factive tablet } \\
\cline { 2 - 3 } & \multicolumn{2}{c}{ Proposed method } & \multirow{2}{*}{$\begin{array}{c}\text { Reported } \\
\text { method }\end{array}$} \\
\cline { 2 - 3 } Method A & Method B & $99.94^{\mathrm{b}}$ \\
\pm SD & $100.28^{\mathrm{a}}$ & 100.5 & 0.82 \\
Variance & 0.901 & 0.5 & 0.67 \\
$t$ test & 0.811 & 0.25 & \\
F test & 0.29 & 0.56 & 5 \\
$\mathrm{n}$ & 1.2 & 0.37 & 5 \\
\hline
\end{tabular}

\section{Elucidation of the reaction product of gemifloxacin mesylate and PMA by means of IR}

The IR spectrum of gemifloxacin showed characteristic bands at 3177 (CH aromatic), $2929 \mathrm{~cm}^{-1}$ (CH aliphatic), $1772 \mathrm{~cm}^{-1}$ ( $\mathrm{C}=\mathrm{O}$ acidic), $1708 \mathrm{~cm}^{-1}$ and $1632 \mathrm{~cm}^{-1}(\mathrm{C}=\mathrm{O}$ aromatic $)$ and 3504 $\mathrm{cm}^{-1}$ (- $\mathrm{NH}_{2}$ primary amino group). On the other hand, the IR spectrum of PMA displayed characteristic strong broad band at $3419 \mathrm{~cm}^{-1}(\mathrm{OH})$ and bands at 1870, 1830, 1797, 1742 and 1701 $\mathrm{cm}^{-1}(\mathrm{P}=\mathrm{O})$. The IR spectrum of the formed ion associate showed both bands corresponding to the drug and PMA as $\mathrm{C}=\mathrm{O}$ (acidic) at $1773 \mathrm{~cm}^{-1}$ and $\mathrm{C}=\mathrm{O}$ (aromatic) at 1798 and $1636 \mathrm{~cm}^{-1}$ in addition to strong broad band at $3422 \mathrm{~cm}^{-1}$. The above arguments indicate that an ion associate has been formed (figures 8-10)

\section{CONCLUSION}

The data of the previously proposed methods reveal that the proposed methods are simple, accurate, and sensitive with good precision and accuracy which made it more advantageous when compared with many of the reported methods in having higher sensitivity. Also with these methods, the analysis can be done at low cost without losing accuracy. In comparison with the chromatographic methods, the proposed methods are advantageous as HPLC and GLC require complex and expensive equipment, intensive sample preparation, and personnel skilled in chromatographic techniques. In addition that HPLC and GLC are not available especially in developing countries. So, the proposed methods can be used as alternative methods for determination of GEM in the pure form and in pharmaceutical formulations in addition to application in biological human urine. 
Financial support and sponsorship: Nil

Conflict of Interests: There are no conflicts of interest.

\section{REFRENCES}

Al-Hadiya B. M., Khady A. A., et al. Validated liquid chromatographic-fluorescence method for the quantitation of gemifloxacin in human plasma. Talanta, 2010; 83: 110-116.

Al-Mohaimeed A. M., Al-Tamimi S. A., et al. New coated wire sensors for potentiometric determination of gemifloxacin in pure form, pharmaceutical formulations and biological fluids. Int. J. Electrochem. Sci, 2012; 7: 12518-12530.

Blondeau J. M. Fluoroquinolones: mechanism of action, classification, and development of resistance. Survey of ophthalmology, 2004; 49: S73-S78.

Cho S. I., Shim J., et al. On-line sample cleanup and chiral separation of gemifloxacin in a urinary solution using chiral crown ether as a chiral selector in microchip electrophoresis. Journal of ChromatographyA, 2004; 1055: 241-245.

Doyle E., Fowles S., et al. Rapid determination of gemifloxacin in human plasma by high-performance liquid chromatography-tandem mass spectrometry. Journal of Chromatography B: Biomedical Sciences and Applications, 2000; 746: 191-198.

Ebraheem S. A., Elbashir A. A., et al. Spectrophotometric methods for the determination of gemifloxacin in pharmaceutical formulations. Acta Pharmaceutica Sinica B, 2011; 1: 248-253.

Elbashir A. A., Saad B., et al. Validated stability indicatingassay of gemifloxacin and lomefloxacin in tablet formulations by capillary electrophoresis. Journal of Liquid Chromatography \& Related Technologies, 2008; 31: 1465-1477.

Food and Administration D. FDA guidance for industry: bioanalytical method validation. Rockville, MD: US Department of Health and Human Services. Food and Drug Administration, Center for Drug Evaluation and Research, 2001; 1: 124-129.

Gouda A. A., Amin A. S., et al. Spectrophotometric Determination of Gemifloxacin Mesylate, Moxifloxacin Hydrochloride, and Enrofloxacin in Pharmaceutical Formulations Using Acid Dyes. Journal of analytical methods in chemistry, 2014; 2014 :

Guideline I. H. T. Validation of analytical procedures: text and methodology. Q2 (R1), 2005; 1 :

Gumustas M. and Ozkan S. A. Simple, sensitive and reliable LC-DAD method of gemifloxacin determination in pharmaceutical dosage forms. Turkish Journal of Pharmaceutical Sciences, 2012; 9: 161170.

Hassan S. S. U., Hayat U., et al. Spectrophotometric method for the determination of Gemifloxacin mesylate in pure and tablet dosage form. Pak. J. Pharm. Sci, 2014; 27: 1171-1174.
Kaiser M., Grünspan L. D., et al. Reversed phase liquid chromatography method with fluorescence detection of gemifloxacin in rat plasma and its application to the pharmacokinetic study. Journal of Chromatography B, 2011; 879: 3639-3644.

Lopez H., Stepanik D., et al. Comparative in vitro activity of gemifloxacin against gram-positive and gram-negative clinical isolates in Argentina. Diagnosticmicrobiology and infectious disease, 2001; 40: 187192.

Martindale W. and Sweetman S. C. 1999. Martindale: the complete drug reference.Book Martindale: the complete drug reference. Pharmaceutical press London.

Nageswara Rao R., Naidu C., et al. Determination of gemifloxacin on dried blood spots by hydrophilic interaction liquid chromatography with fluorescence detector: application to pharmacokinetics in rats. Biomedical chromatography, 2012; 26: 15341542.

Robledo V. R. and Smyth W. F. A study ofthe analytical behaviour of selected new molecular entities using electrospray ionisation ion trap mass spectrometry, liquid chromatography, gas chromatography and polarography and their determination in serum at therapeutic concentrations. Analytica chimica acta, 2008; 623: 221-230.

Roy B., Das A., et al. Determination of gemifloxacin in different tissues of rat after oral dosing of gemifloxacin mesylate by LCMS/MS and its application in drug tissue distribution study. Journal of pharmaceutical and biomedical analysis, 2010; 52: 216-226.

Sultana N., Arayne M. S., et al. Validated method for the determination of Gemifloxacin in bulk, pharmaceutical formulations and human serum by RP-HPLC: in vitro applications. Journal of the Brazilian Chemical Society, 2011; 22: 987-992.

Yoe J. H. and Jones A. L. Colorimetric determination of iron with disodium-1, 2-dihydroxybenzene-3, 5-disulfonate. Industrial \& Engineering Chemistry Analytical Edition, 1944; 16: 111-115.

Zhao F., Zhao W. h., et al. Chemiluminescence determination of gemifloxacin based on diperiodatoargentate (III)-sulphuric acid reaction in a micellar medium. Luminescence, 2013; 28: 108-113.

\section{How to cite this article:}

Zidan D., Ismaiel OA, Hassan WS, Shalaby A. Simple Spectrophotometric,Conductometric and Spectroscopic Methods for Determination of Gemifloxacin in Pure, Pharmaceutical Dosage Form and Human Urine. J App Pharm Sci, 2016; 6 (12): 136-143. 